\title{
Problems and Countermeasures of Wisdom pension in China-- A Case Study of Xinyang, Henan Province
}

\author{
Changze Zhang ${ }^{1, a}$ \\ ${ }^{1}$ Wuhan New Channel, Wuhan, Hubei Province, China
${ }^{a}$ Zoey01rr@icloud.com

\begin{abstract}
At present, aging has gradually evolved into a serious challenge for China's development. Despite that the Internet has now been widely popularized, most elderly groups are excluded due to various factors and difficulties, and are regarded as vulnerable groups in the new technology. Consequently, this work analyzes the positive impact of the Internet on the elderly vulnerable groups based on the existing relevant research with the wisdom pension in Xinyang, Henan Province as an example. Explores the difficulties of the elderly vulnerable groups in using the Internet. In order to provide guidance for the government and enterprises to better promote the use of the Internet in the elderly vulnerable groups, and thereby, enabling the elderly vulnerable groups to enjoy and appreciate the Internet life.
\end{abstract} \\ ABSTRACT
}

Keywords: Aging, Internet, Wisdom pension

\section{INTRODUCTION}

China is one of the fastest-growing aging countries in the world, and pension has evolved into a high-profile social issue. The development of aging, especially in today's rapid popularization of network technology. Making internet use increasingly problematic for older people The online generation gap is considered as a more prominent social pension challenge. From the point of view of the Internet use of the elderly in China, this paper focuses on the national policy of "Internet + providing for the aged", and analyzes the practice of wisdom pension for the aged in Xinyang City, Henan Province, hoping to provide reasonable suggestions for the development of China's wisdom pension for the aged in the future through specific cases.

\section{CHINA'S AGING AND SMART WISDOM PENSION}

\subsection{Status quo of aging in China}

China, as the most populous country in the world, has become the country with the largest elderly population, and the aging is accelerating promptly. In 1999, people over the age of 60 accounted for $10 \%$ of the total population, which marks that China has officially entered the stage of aging. It has been more than two decades. According to the seventh national census data of the National Bureau of Statistics, the number of people aged 60 and above is 264.02 million, accounting for $18.70 \%$, of which 190.64 million are aged 65 and above, accounting for $13.50 \%$.

What is incompatible with the reality of China's growing aging is that nowadays a large number of Chinese elderly seldom use the Internet. As a result, the number of elderly netizens is insufficient, and the elderly have become vulnerable groups in the popularization of Internet technology. Although the number of elderly people using the Internet is increasing, according to the 48th Statistical Report on China's Internet Development in China released by the China Internet Network Information Center, only 12.2\% of netizens aged 60 and above account for the age distribution of netizens, and even if netizens over 50 are added, it only accounts for $28 \%$. This shows that there are a large number of elderly people who hardly use the Internet.

\subsection{The elderly and the Internet}

For most software developers, the development of the elderly is not taken into account, ignoring the initiative of the elderly. As a result, they encounter difficulties in using smart devices, causing this group to feel at a loss about the Internet. For example, since the 
health code was launched in China, there have often been incidents such as elderly people unable to use health codes to get in and out of park scenic spots, being refused by buses, etc. The "code-scanning dilemma" group and related incidents have also received increasing attention from public opinion. In March 2020, people on the platform of the north square of Zhenjiang Railway Station in Jiangsu saw this scene when taking a bus: Some elderly people who use mobile phones for the elderly are forced to get out of the car because the bus company has a mandatory rule that passengers must scan the code before the driver can start the vehicle. There is an uncle here who has been reluctant to get off the bus, and has been deadlocked for more than 20 minutes. For another example, in mid-June 2020, an old man in Harbin was denied boarding by the driver because he did not have a health code when riding a bus. The old man claimed that he was old and did not have a health code, but the driver responded that "even people in their 70s or 80s have to scan the code". Later, the driver called the police, and the police arrived and took the old man away.

According to the China Comment, in the relevant survey, the number of rural netizens is 195 million, while the rural elderly "regularly surf the Internet" accounts for about $0.9 \%$. The number of elderly netizens has a significant gap between urban and rural areas. Nowadays, many elderly people do not use today's smart devices and still stay in the traditional way of life. For example, Grandma Liu in Xiyanghe Village, Huai'an County, Zhangjiakou City, Hebei Province, can only make phone calls with push-button mobile phones. If video chat is needed, relatives in the same village will bring mobile phones to help her connect with her children by video. In the village where Granny Liu lives, most of them are old people, and there is basically no sign of "digital life". [1]In addition, although some elderly people can use the basic chat functions of Wechat, it is still difficult for them to do slightly more complicated operations such as online shopping, taxi hailing and mobile payment. Grandpa Liu, from Zhangjiakou, Hebei Province, has learned to chat on Wechat, but is stuck in the process of checking social security qualifications. This process needs to be completed online, but Grandpa Liu really doesn't know how to operate it, so he finished it with the help of young people. In addition to the obstacles to the use of smart devices.

\subsection{Basic concepts}

\subsubsection{Wisdom pension}

In 1992, the International Communication Center formally put forward the concept of "smart community". In 1996, the world's first smart community project was launched by San Diego State University in the United
States and the California government. [2]The rise of smart (earth-city-community) construction in the world was at the end of 2008, after the American IBM company put forward the concept of "smart earth". Since 2012, with the promotion of the government, the construction of smart communities in China has gradually completed an all-round upgrade from the practical level and information to the promotion of government services and governance.[3] The new pension model of smart community comes into being with the development of big data, cloud computing, Internet and Internet. It provides multi-faceted services such as electronic medical records, auxiliary services, health education, publicity and so on through online digital information service platform and offline health service model, which provides an opportunity for health management of the elderly. Compared with the traditional community, the smart community makes full use of new information technology, smart home and other advanced means to achieve digital and intelligent services, deepen the connotation of traditional community services, expand the content of services, and promote the development of wisdom pension services in a more efficient and convenient way.[4] Smart community is not only human living space or government urban planning and management space, but also human social space. Consequently, the connotation of smart community should reflect the concept of people-oriented, so as to provide convenience and enhance the happiness index of residents. It should aim at creating a warm community environment, devote itself to promoting the intelligent life of residents and building the design idea of a harmonious society, and the government and society should cooperate with modern information technology, emerging intelligent industries, intelligent equipment and new community design schemes, and ultimately complete the "housing" project of people's livelihood in an ideal and effective manner.

For example, Shenggao Dacheng Community in Xishan District is a typical "smart community pension $+"$ pilot project in Yunnan, which is committed to building a doctor-care-combined wisdom pension community that combines health, wisdom, excellent environment and pension. Shenggao Dacheng Community established the only "five-in-one" community co-building system in Yunnan Province in 2012, which provides intelligent information services for people of all ethnic groups, laying a foundation for the further development of medical care combined with intelligent health care in the community. At the beginning of 2018, the Yunnan provincial party committee and provincial government further focused on highlighting the advantages and put forward the idea of building a smart service cloud platform. Specifically, the platform will cooperate with the New Kunhua Hospital of the first people's Hospital of Yunnan 
Province to collect the health status of patients and provide personalized medical services for patients through the expert team and intelligent equipment of the New Kunhua Hospital. On this platform, doctors are enabled to monitor patients' conditions through home devices such as smart wrists. Even if they are far away from patients, doctors have the ability to keep abreast of their demands. In addition, this platform also contributes to solving patients' psychological problems. The purpose of this project is to explore the operation mode of Internet + 's pension service, and strive to create a demonstration pilot of the combination of medical care and wisdom pension, so as to provide a full range of high-quality services for community residents and the elderly.

\section{WISDOM PENSION POLICY}

The Chinese government attaches great importance to the construction of wisdom pension and regards "Internet + providing for the aged" as the focus of its pension policy. The Opinions on Promoting the Healthy Development of Pension services issued by the General Office of the State Council requires a sound policy system in which the elderly can be cared for and young children can be nurtured, and community services at home can be optimized. Firstly, we should expand multi-party participation and multi-modal service supply; enhance family care capabilities and help family members improve care capabilities; optimize home community services, develop a centralized management and operation community elderly care network; improve the service level of public institutions, strengthen the construction of public and public nutrition institutions; promote the transformation of training and recuperation resources to develop pension services; encourage the central and eastern regions with rich training and recuperation resources and large demand for elderly care to make breakthroughs and focus on advancement; broaden the supply channels of inclusive services and guide financial institutions to improve service quality and efficiency. Secondly, we should emphasize the creation of an innovative, integrated, inclusive and open development environment; the promotion of the integrated development of health and care, deepen the organic integration of medical care, develop an pension service complex, and support the continued elderly care in homes, communities, and institutions based on the health status of the elderly; and the strengthening of product research and development and innovative design, promote the upgrading of product manufacturing, and cultivate new forms of smart care for the elderly; strengthen the construction of a livable environment, and promote the formation of a number of demonstration cities and communities for the development of vitality.
In addition, the Ministry of Industry and Information Technology issued the Circular on Effectively Solving the Difficulties of The Elderly in The Use of Smart Technology to Facilitate the Use of Intelligent Products and Services by The Elderly (the Circular) on 19 February 2021. The Circular focuses on providing better telecommunications services for the elderly, carrying out special actions on aging and barrier-free transformation of the Internet, expanding the supply of aging smart terminal products, and effectively ensuring the safe use of intelligent products and services for the elderly, enabling the elderly can have more sense of achievement, happiness and sense of security in the development of information technology. In April 2021, the Ministry of Industry and Information Technology issued General Design Code for Aging of Internet Websites and General Design Code for Aging of Mobile Internet applications (APP), which put forward specific requirements in terms of service principles and technical requirements. This has created convenient conditions for middle-aged and elderly netizens to integrate more deeply into Internet life and share Internet dividends, [5] indicating that the Chinese government has begun to pay more attention to wisdom pension and is willing to give greater policy support.

\section{CASE: THE STATUS QUO, PROBLEMS AND REASONS OF THE SMART COMMUNITY PENSION SERVICES IN XINYANG CITY}

\subsection{The status quo of pension services in smart communities in Xinyang City}

According to the Department of Civil Affairs of Henan Province and the Department of Finance of Henan Province, the second batch of pilot areas for the construction of wisdom pension service platform in Henan Province in 2020 were announced respectively. In Xinyang City, there are two places on the list, namely Hanhe District and Xinxian County in Xinyang City. There are a total of 5 pilot areas in the province. (Notes). Nowadays, the old-age service security work in Xinyang City has begun to take shape. The elderly are also allowed to enjoy old-age services and are at the forefront of the province, but there remains a huge gap from reaching the elderly plan of Xinyang City.

At present, $19.27 \%$ of the population in Xinyang City is over 60 years old, and the number of migrant workers remains at about 2.3 million all the year round. The elderly population in Xinyang City has a large base and rapid growth, especially in rural areas, where the aging phenomenon is more serious. The Xinyang Civil Affairs Department selected Daifan Village in Xinxian County as a pilot based on the status quo of the old district. It starts with getting through the blocking points, 
identifying the focal points, and eliminating the pain points, and is guided by "Party Building+" to empower "Internet+" and "Social Organization+". The role of left-behind women's "pillar" is fully brought into play, and they are required to take good care of the elderly and children. As a result, the "Daifan model" of home care for the elderly was summarized. In addition, the "Three Stay-Behind Service Centers" have been established, and a four-level pension service platform has been established at the city, county, township and village levels. At the same time, it tries to utilize the "company + " approach to solve a series of problems such as home care, childcare, and assistance for the disabled, fully utilize and innovate various civil affairs elements, and continuously optimize the structural reforms on the supply side of pension services. In addition, Xinyang City also relies on the community day care center for the elderly to set up a community pension service station, which provides daily services such as meal supply, personal care, spiritual culture, health and rehabilitation, leisure and entertainment for the self-care elderly and semi-self-care elderly in the community. By 2022, it is expected to achieve full coverage of the city's urban community elderly service stations.

Table1: Xinyang City Home and Community Pension service Reform Pilot Project Implementation Task Breakdown Table

\begin{tabular}{|c|c|c|c|c|c|c|c|c|c|c|}
\hline \multirow[b]{2}{*}{ Unit } & \multirow[b]{2}{*}{$\begin{array}{c}\text { Number of urban } \\
\text { communities }\end{array}$} & \multirow[b]{2}{*}{$\begin{array}{c}\text { Number of rural } \\
\text { communities } \\
\text { (villages) }\end{array}$} & \multirow[b]{2}{*}{ Duration } & \multicolumn{4}{|c|}{ Number of target tasks } & \multirow[b]{2}{*}{\begin{tabular}{|c|} 
Training \\
coverage \\
rate of \\
elderly care \\
workers \\
$(\%)$
\end{tabular}} & \multirow[b]{2}{*}{$\begin{array}{l}\text { Number of } \\
\text { smart elderly } \\
\text { service } \\
\text { information } \\
\text { platforms }\end{array}$} & \multirow[b]{2}{*}{$\begin{array}{l}\text { Number of } \\
\text { professional } \\
\text { social } \\
\text { organization } \\
\text { senior care } \\
\text { service brands } \\
\text { cultivated }\end{array}$} \\
\hline & & & & $\begin{array}{l}\text { Rural } \\
\text { "Three-Stay } \\
\text { Behind" } \\
\text { Service } \\
\text { Center }\end{array}$ & \begin{tabular}{||c|} 
Urban \\
comprehensive \\
community pension \\
service center \\
(community \\
embedded elderly \\
care institution)
\end{tabular} & \begin{tabular}{|c} 
Urban \\
community \\
elderly service \\
station
\end{tabular} & $\begin{array}{c}\text { Rural } \\
\text { community } \\
\text { (village) } \\
\text { elderly service } \\
\text { station }\end{array}$ & & & \\
\hline \multirow{3}{*}{ Shihe District } & \multirow{3}{*}{79} & \multirow{3}{*}{157} & 2020 & 3 & 3 & 56 & 63 & $50 \%$ & & 1 \\
\hline & & & 2021 & 6 & 6 & 73 & 79 & $70 \%$ & & 2 \\
\hline & & & 2022 & 8 & 8 & 79 & 94 & $90 \%$ & 1 & 3 \\
\hline \multirow{3}{*}{$\begin{array}{l}\text { Pingqiao } \\
\text { District }\end{array}$} & \multirow{3}{*}{28} & \multirow{3}{*}{209} & 2020 & 5 & 1 & 20 & 30 & $50 \%$ & & 1 \\
\hline & & & 2021 & 10 & 3 & 25 & 70 & $70 \%$ & 1 & 2 \\
\hline & & & 2022 & 14 & 5 & 28 & 125 & $90 \%$ & & 3 \\
\hline \multirow{3}{*}{$\begin{array}{c}\text { Luoshan } \\
\text { District }\end{array}$} & \multirow{3}{*}{20} & \multirow{3}{*}{225} & 2020 & 6 & 1 & 10 & 110 & $50 \%$ & & 1 \\
\hline & & & 2021 & 12 & 2 & 18 & 120 & $70 \%$ & 1 & 2 \\
\hline & & & 2022 & 17 & 3 & 22 & 230 & $90 \%$ & & 3 \\
\hline \multirow{4}{*}{$\begin{array}{l}\text { Hengchuan } \\
\text { County }\end{array}$} & \multirow{4}{*}{20} & \multirow{3}{*}{269} & 2020 & 6 & 1 & 8 & 60 & $50 \%$ & & 1 \\
\hline & & & 2021 & 12 & 3 & 15 & 169 & $70 \%$ & & 2 \\
\hline & & & 2022 & 17 & 4 & 20 & 269 & $90 \%$ & 1 & 3 \\
\hline & & & 2020 & 6 & 1 & 10 & 65 & $50 \%$ & 1 & 1 \\
\hline \multirow[t]{2}{*}{ Xi County } & \multirow[t]{2}{*}{43} & 321 & 2021 & 12 & 2 & 25 & 130 & $70 \%$ & & 2 \\
\hline & & & 2022 & 18 & 3 & 43 & 193 & $90 \%$ & & 3 \\
\hline & & & 2020 & 5 & 1 & 17 & 108 & $50 \%$ & & 1 \\
\hline $\begin{array}{l}\text { Weibin } \\
\text { County }\end{array}$ & 24 & 271 & 2021 & 10 & 3 & 22 & 136 & $70 \%$ & & 2 \\
\hline & & & 2022 & 15 & 4 & 24 & 163 & $90 \%$ & 1 & 3 \\
\hline & & & 2020 & 6 & 1 & 10 & 138 & $50 \%$ & 1 & 1 \\
\hline Guangshan & 14 & 346 & 2021 & 12 & 2 & 13 & 173 & $70 \%$ & & 2 \\
\hline & & & 2022 & 17 & 2 & 14 & 208 & $90 \%$ & & 3 \\
\hline & & & 2020 & 6 & 1 & 10 & 144 & $50 \%$ & & 1 \\
\hline Shangcheng & 14 & 360 & 2021 & 12 & 2 & 13 & 180 & $70 \%$ & 1 & 2 \\
\hline & & & 2022 & 17 & 2 & 14 & 216 & $90 \%$ & & 3 \\
\hline & & & 2020 & 5 & 1 & 8 & 78 & $50 \%$ & & 1 \\
\hline Xin County & 11 & 195 & 2021 & 10 & 1 & 10 & 98 & $70 \%$ & 1 & 2 \\
\hline & & & 2022 & 15 & 1 & 11 & 117 & $90 \%$ & & 3 \\
\hline & & & 2020 & & 1 & 25 & 3 & $50 \%$ & & 1 \\
\hline Yangshan & 35 & 3 & 2021 & & 2 & 32 & 3 & $70 \%$ & & 2 \\
\hline & & & 2022 & & 3 & 35 & 3 & $90 \%$ & & 3 \\
\hline & & & 2020 & & 0 & 1 & 7 & $50 \%$ & & 1 \\
\hline Jigongshan & 2 & 18 & 2021 & & 1 & 2 & 9 & $70 \%$ & & 2 \\
\hline & & & 2022 & 1 & 2 & 2 & 11 & $90 \%$ & & 3 \\
\hline & & & 2020 & & 0 & 1 & 2 & $50 \%$ & & 1 \\
\hline Shangtianti & 1 & 5 & 2021 & & 1 & 1 & 3 & $70 \%$ & & 2 \\
\hline & & & 2022 & & 1 & 1 & 5 & $90 \%$ & & 3 \\
\hline & & & 2020 & & 0 & 3 & 0 & $50 \%$ & & 1 \\
\hline Nanwan & 7 & 4 & 2021 & & 1 & 4 & 2 & $70 \%$ & & 2 \\
\hline & & & 2022 & & 2 & 7 & 4 & $90 \%$ & & 3 \\
\hline Hich tech 70 & 5 & 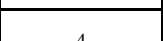 & 2020 & & 0 & 3 & 3 & & & 1 \\
\hline High-tech Zone & 5 & 4 & 2021 & & 1 & 4 & 4 & & & 2 \\
\hline
\end{tabular}




\section{\begin{tabular}{l|l|l|l||l|}
\hline & & 2022 & &
\end{tabular} \\ 4.2 Implementation case of wisdom pension in Xinyang City}

Facing the actual situation, Xinyang City, Henan Province, explored the "Daifan Mode" of "Red Vest" + "Sunset Red" + "Little Red Star". The home care service brings together scattered elderly people and enables them to gain energy in the organization. The Daifan Village Senior Citizens Association stipulates that all elderly people over 60 years old in the village automatically become members of the Senior Citizens Association. It starts with the employment of left-behind women and activates the "red vest" to play the role of left-behind women. Daifan Village selected left-behind women, set up special filial nursing positions, and hired them to provide door-to-door services for the elderly in the village, forming an pension service team with rural characteristics. On the basis of daily home care services, the 9th, 19th, and 29th of each month are designated as Respect for the Elderly Day, and the general service objects are concentrated on providing spiritual comfort home services; Tuesdays and Fridays are designated as Respect for the Elderly Days, which ensures the normalization and institutionalization of home care services. Daifan Village adopts the "Internet + elderly care" model, and the elderly association directly sends the service needs of the elderly to the filial caregiver through the home pension service system and mobile phone APP. After the caregiver completes a service, the APP automatically records the service track. The Senior Citizens' Association regularly settles service remuneration for the caregivers based on the monthly service data, which improves the family income and work motivation of the caregivers. The close interpersonal relationship in the village, abundant social capital, perfect grassroots organization, rural land system, and surplus labor constitute an important resource for solving the "three stay-at-home" problem. In the useful attempts and bold innovations, Daifan Village discovered the "village perspective" and the "acquaintance social perspective" of the rural "three stays behind", and found new ideas for solving the rural "three stays" problem.

Xinyang City actively explores the application of "Internet + " in home and community pension services, establishes an information platform, realizes big data management, and uses information and standardized management to improve the quality of pension services. On the basis of operating the 12349 information platform, in 2020, another 1.94 million yuan was invested to build a four-level old-age service information network platform at city, county, township and village, which smooth the communication and docking between pension demand and service supply, \begin{tabular}{ll|c|c||c|} 
& 5 & 4 & & 3 \\
\hline realize & the information & interconnection & among
\end{tabular} government, market and residents, and provide intelligent services for home and community pension.[6]

\subsection{Problems of wisdom pension services in Xinyang City and government countermeasures}

The construction of elderly care in some communities needs to be further strengthened. For example, Xianling Garden Community in Xinyang City does not provide basic community pension services. A medical clinic in this community was opened spontaneously by community residents, but this is far from meeting the basic needs of the community. Only some basic diseases such as colds and fever can be treated because medical resources are limited. Similar to the Xianling Garden District, the medium-and low-grade pension community does not provide too much medical convenience to the elderly, mainly because the single-function service requires investment, less manpower and small scale. What's more, the supervision system and evaluation system of some residential areas are not perfect, resulting in no residual capacity to supervise the safety of facilities, fire protection, food and so on in old-age service institutions and places. Of course, there are also relatively well-equipped communities, such as the five-star pension service center in Hudong Street, Huanghe District. With the help of the wisdom pension service platform, the center provides home cleaning, community day care, pension institutions and other services for the elderly in the community. It is worth noting that the team of old-age service professionals is a problem that must be solved to improve the old-age service system. At present, the staff engaged in pension services can only provide basic low-level services to the elderly because most of them have not received professional pension service education, and cannot provide special medical care and psychological counseling for the elderly to meet their medical rehabilitation needs.

It is worth noting that the team of old-age service professionals is a problem that must be solved to improve the old-age service system. At present, the staff engaged in pension services can only provide basic low-level services to the elderly because most of them have not received professional pension service education, and cannot provide special medical care and psychological counseling for the elderly to meet their medical rehabilitation needs. Subsequently, Xinyang City continues to strengthen the construction of old-age service personnel, implement actions to improve the ability of old-age service personnel, and establish three-level training mechanisms at city, county and 
pension institutions (organizations). The skills training of old-age service personnel will be included in the Xinyang Functional Skills Upgrading Action Plan, and free training will be carried out. By 2022, it will complete the training of 251 nursing home directors, 6400 caregivers (family caregivers) and 320 elderly social workers. With the continuous training of new pension service personnel in Xinyang City, this phenomenon may be effectively solved.

\section{POLICY RECOMMENDATIONS FOR THE FUTURE DEVELOPMENT OF CHINA'S WISDOM PENSION}

\subsection{Perfect laws and regulations related to the Internet pension}

Law is the most important instrument of governing the country, and good law is the premise of good governance. In terms of Internet pension, China still lacks binding and more enforceable legal provisions. This implies that we should strive to improve the relevant legislation and, according to the weak position of the elderly, provide special protection of rights and interests while giving general protection, combined with the comprehensive strength of the medical economy of various places, so as to formulate reasonable and comprehensive local laws and regulations, and form a three-dimensional and interlinked medical security system from the local to the central government.

\subsection{The government strengthens regulation and guidance and establishes a community wisdom pension cooperation system}

Market regulation is not omnipotent, especially in the field of social security. While further relaxing the access to the "Internet + " community pension market, we should also further protect the legitimate rights and interests of the elderly through macro-control. Therefore, it is urgent to establish a community old-age cooperative medical insurance system. The construction of community old-age cooperative medical insurance needs to consider two aspects, social overall planning and mutual assistance. [7]Therefore, more medical insurance institutions, especially Internet enterprises, should be encouraged to get involved in the cause of providing for the aged, and the government should strengthen standardization and guidance to promote the orderly development of the wisdom pension cooperation system.

\subsection{Establish a local wisdom pension industry association}

As a non-profit organization, industry associations are a bridge for communication and mutual assistance between enterprises and the government, and they play a role in planning and supervision. For example, the "standard committee" and "inspection committee" established in Beijing for pension services have played a good exemplary role in establishing local elderly care industry associations, which should be vigorously promoted throughout the country. [8]It is suggested that China Aging Industry Association should take the lead and join hands with local enterprises to establish local wisdom pension industry associations, so as to better safeguard the legitimate rights and interests of enterprises, standardize the wisdom pension market, and establish a good image of the pension industry.

\subsection{Establish a national unified real-time wisdom pension information platform}

In the information age, the timeliness and accuracy of information is the basis for designing personalized wisdom pension solutions and the prerequisite for ensuring the safety of Internet medical care and nursing care. This indirectly reminds us of the importance of establishing a national real-time updated information platform. This platform will use big data technology to classify the various service needs of the elderly and reflect them in the form of dispatch orders, and then the corresponding companies will complete the orders, which will enable the community to better allocate and utilize the resources for the elderly. [9]In addition, the way of binding service providers and pension groups through the network is also beneficial to improve the accuracy of pointing in accountability.

\subsection{Enhance the level of professionals}

The establishment of a sufficiently perfect and feasible training system for professional old-age service personnel is the top priority for the development of the cause of providing for the aged. Domestic care services, nursing care services and other markets are not yet mature, the entry threshold is low, and some old-age nurses do not even need basic nursing knowledge and technical requirements. In this regard, the elderly often feel that the quality of service is not proportional to the price. This, coupled with the insufficient number of professionals who can provide high-quality pension services, leads to a shortage of supply. [10]Accordingly, it is suggested to increase the number of jobs in the pension market while improving the level of professionals and promoting the upgrading and transformation of the pension market, which can not only alleviate the employment pressure of the working population of all ages, but also meet the consumption needs of the elderly. 


\section{CONCLUSION}

This paper has analysed the smart ageing situation in Xinyang City, Henan Province, using a large number of examples and data to derive the current situation of smart ageing in Xinyang City. Xinyang City is at the forefront of smart ageing in China, with large scale elderly service centres and smart communities, and has created a new model. However, there are still some shortcomings that need to be improved. For example, the rules and regulations of the elderly service industry and the training of personnel need to be improved.

\section{REFERENCES}

[1]Zhao L, Li Z (2020). Status quo of the digital life of the elderly: needs vary from person to person, some people become "digital poor households", Rule of Law Daily, August 25, 2020

[2]Huang Y, Zhang T. (2019). Comparison and reflection of domestic and foreign smart community research: concept, evaluation and trend. J. Modern Management Science, vol. 07. 63-65.

[3]Yu D (2015). Research on the Integrated Solution and Model of Internet of Things Community Service: Construction and Operation of Smart Community. National Defense Industry Press, 87.

[4]Wang $X$, Chen $X \quad$ (2015). Smart Communities--Future Homes in the Internet of Things Era. M. Beijing: Publishing House of Electronics Industry, 56.

[5]China Internet Information Center (2021): The 48th "Statistical Report on Internet Development in China", September 15, 2021, see the website of China Internet Information Center, http://www.cnnic.net.cn/hlwfzyj/hlwxzbg/hlwtjbg/ 202109/P020210915523670981527.pdf

[6]Zhou Qiang (2021), "Red Vest" + "Sunset Red" + "Little Red Star"-"Daifan Mode" to solve the problem of "three staying behind" in rural areas, http://mzj.xinyang.gov.cn/news-51231.html

[7]Yao L. (2015). Protection of the rights and interests of the elderly in an aging society. Journal of Kaifeng College of Education. vol. 11. 242-243

[8]Xiao F. (2018). Economic Analysis of the Optimal Allocation of Medical and Health Resources in China. Economic Research Guide. vol. 06. 183-184

[9]Wen H. Wang Y. (2017). "Internet + Home Care" Service Platform Construction and Implementation Path, Journal of Hebei University. vol. 06. 138-146
[10]Li X. Hu L. (2020). Exploring the community home care model under the Internet vision, modern business industry. vol. 15. 49-51 